\title{
Resection vs. ablation for lesions characterized as resectable- ablative within the colorectal liver oligometastases criteria: a propensity score matching from retrospective study
}

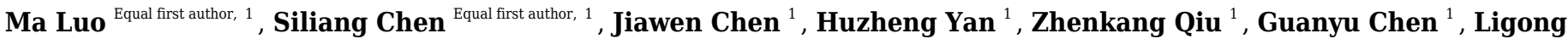

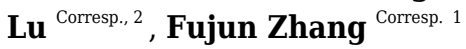 \\ ${ }^{1}$ Sun Yat-sen University Cancer Center; State Key Laboratory of Oncology in South China; Collaborative Innovation Center for Cancer Medicine, \\ Guangzhou, China \\ ${ }^{2}$ Zhuhai Interventional Medical Center, Zhuhai Precision Medical Center, Zhuhai People's Hospital, Zhuhai Hospital Affiliated with Jinan University, Zhuhai, \\ Guangdong, China
}

Corresponding Authors: Ligong Lu, Fujun Zhang

Email address: luligong1969@126.com, zhangfj@sysucc.org.cn

Background There has been no prospective or retrospective studies reporting the comparison outcome between surgery and ablation for resectable-ablative (lesions could be treated by resection or complete ablation) colorectal liver oligometastases (CLOM). The purpose of this study was to compare the efficacy and prognostic difference in patients who underwent $\mathrm{R} 0$ resection vs. complete ablation within the resectable-ablative CLOM criteria.

Methods From January 2008 to May 2018, a total of 2367 patients diagnosed with colorectal liver metastases were included in this observational study. The metastasis was characterized by only limited to liver with number $\leq 5$, size $\leq 5 \mathrm{~cm}$, and resectable-ablative (lesions could be treated by resection or complete ablation). The evaluated indications, including liver progression-free survival (LPFS), overall survival (OS), survival rates, pattern and number of recurrences, and complications, were compared by using propensity score matching (PSM). The Kaplan-Meier curves were generated, and a log-rank test was performed. The Cox regression model was used for univariate and multivariate analyses to identify predictors of outcomes.

Results 421 consecutive patients were eligible for this study, with 250 and 171 undergoing R0 resection and complete ablation, respectively. PSM identified 145 patients from each group. The 1-, 3-, 5- and 8year OS rates in the resection group and the ablation group were $95.8 \%$ vs. $95.0 \%, 69.8 \%$ vs. $60.1 \%$, $53.6 \%$ vs. $42.5 \%$, and $45.1 \%$ vs. $32.9 \%$ ( $p=0.075)$, respectively. The median LPFS in the resection group was significantly longer than that in the ablation group ( 35 months vs. 15 months, $p=0.011$ ). No statistical difference was found in LPFS between the two groups when comparing $\leq 3 \mathrm{~cm}$ liver metastases. For liver metastasis $>3 \mathrm{~cm}$, the median LPFS in the resection group and ablation group was 11 months and 5 months, respectively $(p=0.001)$. In terms of high risk of clinical risk score (CRS), the resection group showed longer LPFS than the ablation group (median 18 months vs. 10 months, $p=0.043)$.

Conclusion For patients within the CLOM criteria suggesting that liver metastases were resectable as well as ablative, resection could result in longer liver recurrence-free survival than ablation in cases with size $>3 \mathrm{~cm}$ or high risk of CRS. But for $\leq 3 \mathrm{~cm}$ liver metastases, their treatment efficacies were comparable. 
1 Title:

2 Resection vs. ablation for lesions characterized as resectable-ablative within the colorectal liver oligometastases

3 criteria: a propensity score matching from retrospective study

4

5 Authors:

6 Ma Luo*1, Siliang Chen ${ }^{* 1}$, Jiawen Chen ${ }^{1}$, Huzheng Yan ${ }^{1}$, Zhenkang Qiu ${ }^{1}$, Guanyu Chen ${ }^{1}$, Ligong Lu **2, Fujun 7 Zhang**1, MD

9 *Authors contributed equally to this work

$10 * *$ Corresponding author

11

12

\section{Institution:}

${ }^{1}$ Sun Yat-sen University Cancer Center; State Key Laboratory of Oncology in South China; Collaborative Innovation Center for Cancer Medicine, Guangzhou, China.

${ }^{2}$ Zhuhai Interventional Medical Center, Zhuhai Precision Medical Center, Zhuhai People's Hospital, Zhuhai Hospital Affiliated with Jinan University, Zhuhai, Guangdong, P.R. China

\section{Corresponding address:}

Tel.: +86 20 87343907;

Fax: +86 2087343392 .

E-mail address: zhangfj@sysucc.org.cn

Street address: 651 Dongfeng East Road, Guangzhou, Guangdong 510060, China.

Tel.: +86 756-2158358;

Fax: $+86756-2218735$.

E-mail address: luligong1969@126.com

Street address: No.79, Kangning Road, Xiangzhou District, Zhuhai, Guangdong 519000, P.R. China.

\section{Abstract}

Background There has been no prospective or retrospective studies reporting the comparison outcome between surgery and ablation for resectable-ablative (lesions could be treated by resection or complete ablation) colorectal liver oligometastases (CLOM). The purpose of this study was to compare the efficacy and prognostic difference in patients who underwent R0 resection vs. complete ablation within the resectable-ablative CLOM criteria.

Methods From January 2008 to May 2018, a total of 2367 patients diagnosed with colorectal liver metastases were included in this observational study. The metastasis was characterized by only limited to liver with number $\leq 5$, size $\leq 5 \mathrm{~cm}$, and resectable-ablative (lesions could be treated by resection or complete ablation). The evaluated indications, including liver progression-free survival (LPFS), overall survival (OS), survival rates, pattern and number of recurrences, and complications, were compared by using propensity score matching (PSM). The Kaplan-Meier curves were generated, and a log-rank test was performed. The Cox regression model was used for 
univariate and multivariate analyses to identify predictors of outcomes.

Results 421 consecutive patients were eligible for this study, with 250 and 171 undergoing R0 resection and complete ablation, respectively. PSM identified 145 patients from each group. The 1-, 3-, 5- and 8-year OS rates in the resection group and the ablation group were $95.8 \%$ vs. $95.0 \%, 69.8 \%$ vs. $60.1 \%, 53.6 \%$ vs. $42.5 \%$, and $45.1 \%$ vs. $32.9 \%(\mathrm{p}=0.075)$, respectively. The median LPFS in the resection group was significantly longer than that in the ablation group ( 35 months vs. 15 months, $\mathrm{p}=0.011$ ). No statistical difference was found in LPFS between the two groups when comparing $\leq 3 \mathrm{~cm}$ liver metastases. For liver metastasis $>3 \mathrm{~cm}$, the median LPFS in the resection group and ablation group was 11 months and 5 months, respectively $(\mathrm{p}=0.001)$. In terms of high risk of clinical risk score (CRS), the resection group showed longer LPFS than the ablation group (median 18 months vs. 10 months, $\mathrm{p}=0.043)$.

Conclusion For patients within the CLOM criteria suggesting that liver metastases were resectable as well as ablative, resection could result in longer liver recurrence-free survival than ablation in cases with size $>3 \mathrm{~cm}$ or high risk of CRS. But for $\leq 3 \mathrm{~cm}$ liver metastases, their treatment efficacies were comparable.

\section{Introduction}

Colorectal cancer is the third leading cause of cancer deaths in both males and females all over the world (Siegel et al. 2019). Liver is the most frequent metastatic site, and it is estimated that about quarter of patients present with synchronous metastases when they are initially diagnosed and almost $50 \%$ of patients will develop metachronous metastases afterwards (Van Cutsem et al. 2014). Over the past two decades, the clinical outcome of colorectal liver metastases has improved dramatically due to advancement in the treatment regimen and alteration for treatment conception (Van Cutsem et al. 2016).

Colorectal liver oligometastases (CLOM) is a stage of disease characterized as the existence of limited metastases at less than three sites and five or occasionally more lesions. A local treatment approach can be used with a view to improving disease control and prognosis due to its localized features. The current regimen is resection and local ablative treatment. Resection is the most widely used option in liver metastasis and is the most common evidencebased approach, with the 5- and 10-year survival rate and the recurrence rate was $34 \%-58 \%, 25 \%-50 \%$, and $11 \%$, respectively (Abdalla et al. 2004; Chua et al. 2011; Lin et al. 2018). Ablation, one of approaches in the toolbox of local ablative treatment, is a type of minimally invasive treatment that is generally accepted in a wider range of patients with increasing used frequency due to its repeatability, effectiveness, and safety. In the literature concerning ablation, it was reported that the 5- and 10-year survival rate and the tumor control outcome was $31 \%-47.8 \%, 18 \%$, and 32.3\%-48\%, respectively, in these patients (Abdalla et al. 2004; Shady et al. 2016; Solbiati et al. 2012).

However, to date, there has been no prospective study reporting the comparison outcome between the ablation and surgery for this liver disease (Cirocchi et al. 2012). All retrospective studies performed comparison between resection/ablation combinations or alone. Among the studies comparing the result between resection and ablation, favorable efficacy in the former group was reported because the lesion in the latter group was either unresectable, the patient was in a poor condition, or there was inequality in the number of cases (Hur et al. 2009; Lee et al. 2008; Otto et al. 2010; Van Tilborg et al. 2011). Thus, the finding of a better outcome in the resection group might be biased although the basic characteristics were balanced between the two groups. In an ablation study, Evrard et al. reported a survival benefit of ablation treatment in CLOM patients, but the lesions were unresectable, multiple ( $<$ 13), and some of which were recurrent (Evrard et al. 2012). These conditions could lead to bias in the results and could weaken the conclusion of these studies (Dupre et al. 2017; Sofocleous et al. 2011). From a technical aspect, if 
liver metastases from colorectal cancer were resectable-ablative (indicating either resection or complete ablation could be made to eradicate such lesion), was there any difference or what was the difference in the prognostic outcome between patients treated with resection and ablation? The clinical evidence of this comparison is lacking (Wang et al. 2018). Therefore, we conducted this study to investigate the survival and treatment efficacy of resection versus ablation in such two groups from a cohort of CLOM patients.

\section{Materials and Methods}

All procedures performed involving human participants in this study were in accordance with the Declaration of Helsinki (1975) and its later amendments or comparable ethical standards. Institutional Review Board approval was obtained from the independent ethics committee at out center (approval number: 20170302015). Informed consent was obtained from all patients included in this study.

\section{Patient selection and data collection}

A total of 2367 consecutive patients diagnosed with colorectal liver metastases from January 2008 to May 2018 at our center were retrospectively reviewed.

The inclusion criteria were as follows: (1) R0 resection for adenocarcinomas of the colon and rectum; (2) >18 years of age, Eastern Cooperative Oncology Group (ECOG) $<2$; (3) before enrollment, only liver oligometastases (number $\leq 5$, size $\leq 5 \mathrm{~cm}$ ). In patients who received chemotherapy before enrollment, the number of liver metastases should also be limited $\leq 5$; (4) no previous hepatectomy or ablation for liver metastases; (5) before liver resection or ablation, the lesion was technically considered to be resectable-ablative that was qualified to undergo complete both resection and ablation consensus from one interventional radiologist and one hepatobiliary surgeon by reviewing the patient's initial CT or MRI images (Fig. 1). The assessment was performed independently by them who were blinded to the clinical information of the patients. Any disagreement on the assessment result was resolved by final consensus; (6) the liver treatment was implemented successfully. For resection, technical success was defined as R0 resection; for ablation, technical success was referred to the lesion which was completely covered by the ablation defect at the first month of follow-up images according to contrast-enhanced CT or MRI.

The exclusion criteria were as follows: (a) pathological examination was non-adenocarcinoma, such as neuroendocrine carcinoma or gastrointestinal stromal tumor; (b) no detailed medical records or data that could be further analyzed, or loss to follow-up; (c) the regimen was chemotherapy or radiotherapy alone or in combination, or hepatectomy + ablation concurrently; (d) extrahepatic metastases or $>5$ liver metastases at initial diagnosis; (e) liver metastases without R0 resection or complete ablation; (f) the liver lesion was in Segment I, or it was adjacent to the heart, gall bladder, gastrointestinal tract, diaphragm, or large vessel structure within $1 \mathrm{~cm}$ (Fig. 1).

The flowchart of patient selection is shown in Fig. 2.

\section{Ablation treatment}

Ablation was implemented by MWA or RFA. MWA was performed by FORSEA MTC-3C microwave system (Qinghai Microwave Electronic Institute, Nanjing, China) with $2450 \mathrm{MHz}$ frequency and a mean power of $65 \mathrm{~W}$ (range, 50-100 W) for 3-12 minutes per ablation according to the location and the size of lesions. RFA was performed by the radiofrequency system (RF 2000; RadioTherapeutics, Mountain View, CA, USA), with a mean power of $110 \mathrm{~W}$ (range, 40-200 W) for 4-15 minutes each procedure.

Contrast enhancement was routinely performed after the ablation immediately. Repeat ablation was performed 
when a residual tumor or a suspicious area was detected on imaging. After accomplishing complete ablation that the lesion was covered completely by the ablation defect on real-time imaging detection, the needle path was ablated to avoid bleeding or seeding.

\section{Follow-up and efficacy analysis}

The follow-up period was the interval from the date of treatment to death or the last visit by June 1, 2019. According to recurrence patterns, the first site of recurrence was classified as local tumor recurrence that was defined as any new peripheral or nodular enhancement within $1 \mathrm{~cm}$ outside the area of previously treated field; liver new metastasis was categorized as any recurrence remote from the treated site; and extrahepatic recurrence was indicated as any other recurrence outside the liver based on CT or MRI enhancement during follow-up (Stattner et al. 2013).

The primary endpoint was liver progression-free survival (LPFS, which was defined as the duration from treatment to the first event: liver recurrence, death or the last follow-up). The secondary endpoints were overall survival (OS, which was defined as the duration from treatment to the event: death or the last visit), local tumor recurrence rate and pattern, and complications. These indications were compared between the two groups.

\section{Statistical analysis}

To balance the basic condition and to minimize the confounding on selection bias before analysis, propensity score matching (PSM) was used and estimated by a logistic regression model using the following independent variables: age, sex, primary tumor lymph node status, disease-free interval, the number and size of liver metastases, and chemotherapy after resection or ablation. A 1:1 matching ratio between the two groups was set using the nearest-neighbor matching method (caliper $=0.1$ ).

Statistical analysis was performed by IBM SPSS version 22.0 software (SPSS, Chicago, IL, USA) and GraphPad Prism version 6.01 (GraphPad Software, Inc., USA). The results were compared by $\chi^{2}$ tests, Student $t$ test, or Fisher's exact test as appropriate.

The survival curves were calculated and compared by using the Kaplan-Meier method and the log-rank test. Univariate analysis was performed, and any factors showing statistical significance were analyzed by the multivariate Cox hazards model. P value $<0.05$ was considered significance (two-sided).

\section{Results}

\section{Patient characteristics}

The baseline characteristics before PSM are summarized in Table 1. Metastases diameter and chemotherapy after the procedure were significantly different between the two groups $(\mathrm{P}<0.05)$, and these two indices were crucial to the prognosis. After PSM, there were 145 patients in each of the resection and ablation group. Among the selected patients, there was no significant difference in any of the variables listed in Table 2.

\section{Treatment and local control evaluation}

All enrolled patients in the resection group underwent R0 resection. There were 277 lesions in 145 patients, and the mean number of lesions treated per patient was 1.91. In the ablation group, complete ablation was achieved in all enrolled patients and no enhancement lesion was detected within the ablation area at the first month of follow-up imaging. A total of 273 ablation sessions were performed in 145 patients, and the mean number was 1.88 per patient. 
The local tumor recurrence rate in the resection group and the ablation group was $46.20 \%$ and $60.69 \%$ ( $\mathrm{p}=0.013$ ), respectively. The local tumor recurrence rate in the MWA group and the RFA group was $36.58 \%$ and $46.03 \%$ per patient, respectively, without significant difference $(\mathrm{p}=0.251)$, and this rate between these two groups was $31.64 \%$ and $26.96 \%$ per lesion $(\mathrm{p}=0.402)$, respectively. The detailed recurrence pattern and number are listed in Fig. 3 and Table 3.

\section{Survival related outcome}

The median follow-up period and OS in all patients was 32 months (range, 1-133 months) and 60 months, respectively. The entire 1-, 3-, 5-, 8- and 10-year OS rate was $95.4 \%, 65.3 \%, 48.4 \%, 39.4 \%$ and $32.5 \%$, respectively (The survival and recurrence rate at specific year in the two groups are shown in Supplementary Material Table 4). The median OS was 62 months (range, 1-133 months) and 53 months (range, 3-113 months) in the resection and ablation group, respectively ( $\mathrm{p}=0.075$; Fig. $4 \mathrm{a}$ and $\mathrm{b}$ ). Before PSM, the median LPFS in the resection group was longer than that in the ablation group ( 28 months vs. 12 months, $\mathrm{p}=0.03$ ). After PSM, the median LPFS was 35 months in the resection group, which was significantly longer than that of 15 months in the ablation group ( $\mathrm{p}=0.011$; Fig. $4 c$ and d).

\section{Subgroup analysis}

There was no statistical difference in LPFS between the two groups when comparing $\leq 3 \mathrm{~cm}$ solitary or multiple liver metastases. For liver metastasis $>3 \mathrm{~cm}$, the median LPFS in the resection and ablation group was 11 months and 5 months ( $\mathrm{p}=0.001$ ), respectively (Fig. 5a-e).

The LPFS in patients with intravascular tumor thrombus (IVTT) negative for primary tumor was significantly longer than that with IVTT positive ( 35 months vs. 14 months, $\mathrm{p}=0.011$ ). In the subgroup analysis of IVTT positive and negative, respectively, although the median LPFS in the resection group was longer than that in the ablation group, there was no statistical difference ( 18 months vs. 12 months, $\mathrm{p}=0.298 ; 53$ months vs. 23 months, $\mathrm{p}=0.128$, respectively).

The LPFS was significantly shortened in patients with high risk (3 to 5) of clinical risk score (CRS, including the primary tumor node state, CEA level, size and number of liver metastases, and synchronous or metachronous metastases) compared with those with low risk ( 0 to 2 )(40 months vs. 12 months, $\mathrm{p}<0.001$ ). In the subgroup analysis of high risk of CRS, the resection group showed longer LPFS than the ablation group (18 months vs. 10 months, $\mathrm{p}=0.043$, Fig. $6 \mathrm{a}$ and $\mathrm{b}$ ).

For patients that the liver was not the first site of recurrence had longer survival duration than those with the liver was the first site of recurrence (64 months vs. 53 months, $\mathrm{p}=0.032$ ). Likewise, in the subgroup analysis of liver recurrence, patients with early recurrence (occurred within 6 months after liver curative treatment) showed shorter survival outcome than those without early recurrence ( 19 months vs. 40 months, $\mathrm{p}=0.001$, Fig. $6 \mathrm{c}$ and d).

\section{Survival association analysis}

The univariate analysis showed that T4 stage, $\mathrm{N}$ stage positive, metastases diameter $>3 \mathrm{~cm}$, metastases number $>1$, high risk of CRS, ablation treatment, and absence of post-procedure chemotherapy were correlated with shorter LPFS. In the multivariate model, T4 stage (HR 1.511; $\mathrm{P}=0.033$ ), metastases diameter $>3 \mathrm{~cm}$ (HR 2.174; $\mathrm{P}=0.007$ ) and high risk of CRS (HR 1.706; $\mathrm{P}=0.007$ ) were identified as prognostic predictors of shorter LPFS (Supplementary Material Table 5). The forest plot analysis of factors associated with LPFS is shown in Fig. 7. 
206

207

208

209

210

211

212

213

214

215

216

217

218

219

220

221

222

223

224

225

226

227

228

229

230

231

232

233

234

235

236

237

238

239

240

241

242

243

244

245

246

\section{Complications}

Death occurred in two patients of the resection group during hospitalization. Other complications, whose total incidence was $11.7 \%$, included fistula $(n=4)$, peritonitis $(n=3)$, pleural effusion $(n=2)$, pneumothorax $(n=2)$, and subcapsular hematoma $(\mathrm{n}=2)$ (Table 3 ). These patients received pertinent and appropriate treatment, and finally recovered.

\section{Discussion}

In this study, we investigated patients with colorectal metastases only limited in the liver, which were resectableablative. Our results showed that the presence or absence of liver recurrence was one of the important factors affecting the survival duration, indicating the improvement in liver control was crucial to the prognosis and disease management.

The OS rates in the entire group and respective group at specific year in our study were comparable to the results of several other similar studies with a long-term cohort (Abdalla et al. 2004; Chua et al. 2011; Lee et al. 2015; Lin et al. 2018; Shady et al. 2016). The LPFS rates at 1, 3 and 5 years in our ablation group were higher than those patients presented with recurrent (Van Tilborg et al. was about 42\%-20\%) (Van Tilborg et al. 2011), unresectable (Dupre et al. was about 20\%-0) (Dupre et al. 2017) or extrahepatic disease at initial ablation (Siperstein et al. was about 35\%15\%) (Siperstein et al. 2007).

The LPFS before and after PSM in the resection group was longer than that in the ablation group, and the local tumor recurrence rate in the resection group was lower, indicating that resection had an advantage in lower recurrence. In the literature regarding ablation, although Solbiati et al. and Shady et al. reported that the 5- (31$47.8 \%$ ) and 10-year (18\%) survival rates were close to those after surgical resection, the local tumor recurrence rate was higher (40.4-54.0\%). Also, the overall LPFS was shorter in patients treated with ablation compared to surgery, for both initial and recurrent lesions in many other studies (Dupre et al. 2017; Sofocleous et al. 2011; Wang et al. 2018). Recently, two non-inferiority prospective trials called LAVA (Liver resection surgery versus thermal ablation for colorectal Liver Metastases) and COLLISION (Colorectal liver metastases: surgery versus thermal ablation), respectively, are being carried out (Gurusamy et al. 2018; Meijerink et al. 2019). They are aimed on evaluating the treatment efficacy and benefit of thermal ablation compared with resection among patients with small lesions (0-3 $\mathrm{cm})$ characterized by ablatable and resectable. The results are worthy of expectation and publication.

Recurrence is commonly seen in CLOM after curative treatment (Lin et al. 2018). The local tumor recurrence rate in our cohort was within the range of 43.6-57.3\% from other long-time follow-up observations (Otto et al. 2010; Park et al. 2008), but higher than the results presented by Lee et al. and Wang et al, who showed rates of $29.2 \%$ and 40.4\%, respectively (Lee et al. 2016; Wang et al. 2018). Additionally, the local tumor recurrence rate between the MWA and RFA was higher than the result of Takahashi et al (Takahashi et al. 2018). The total case number and follow-up period in their studies were less and shorter than they were in our study, and the report from Lee et al was focused on isolated hepatic metastasis. The resection group showed less liver recurrence at 1-, 3- and 5-year followup than the ablation group, which was in accordance with the results presented by Abdalla et al. and Lee et al (Abdalla et al. 2004; Lee et al. 2015). We also noted that the liver recurrence pattern was different in the two groups. More local tumor recurrences were occurred in the ablation group, while liver new metastases were higher in the resection group, demonstrating that resection was superior in local disease control (treated area) even when R0 ablation and resection were completely implemented, but the first site of recurrence in the liver was not associated

Peer) reviewing PDF | (2019:08:40501:1:1:NEW 18 Nov 2019) 
247

248

249

250

251

252

253

254

255

256

257

258

259

260

261

262

263

264

265

266

267

268

269

270

271

272

273

274

275

276

277

278

279

280

281

282

283

284

285

286

287 with survival (Siperstein et al. 2007). We speculated there were several possible explanations for this result. First, heat injury might induce and stimulate inflammation, and the expression of angiogenesis molecular was increased, promoting tumor progression or metastasis after ablation (Kumar et al. 2018; Ni et al. 2019; Zhang et al. 2017). Second, R0 resection was confirmed by pathology, while complete ablation without microscopic validation. Although a multiposition biopsy was recommended during the ablation procedure, the tissue extracted from a local part in the ablation area might be partial and increase the risk of complications (Sotirchos et al. 2016). Third, the ablative tissue reacting to heat stimulation might present abnormal blood perfusion on contrast-enhanced images, occasionally influenced the determination of reactive hyperemia, and residual or viable tumor (Chan et al. 2015).

IVTT positive in the primary tumor at microscopy represented more obvious aggressive behavior with tumor growth, invasion, and metastasis than those with IVTT negative lesion (Peng et al. 2019). Similarly, when R0 resection or complete ablation was achieved, the LPFS in the ablation group was shorter than that in the resection group when IVTT was positive, although no statistical difference was shown. This suggested that in the high risk of recurrence condition, resection might still be recommended to IVTT positive patients due to its relatively lower recurrence risk compared with that of ablation.

CRS is a comprehensive index associated with prognosis (Fong et al. 1999). Tumor size is an important factor for the ablation effect(Gillams \& Lees 2009). As the size increases $(>3 \mathrm{~cm})$, the possibility of achieving complete ablation decreases and the risk of residual tumor increases. The modified CRS using a cutoff point of $3 \mathrm{~cm}$ instead of $5 \mathrm{~cm}$ for tumor size is optimal for evaluating the outcome between R0 resection and complete ablation (Shady et al. 2016). Our results showed that resection was beneficial for achieving longer LPFS in patients with high risk of CRS, although it was a poorer overall prognosis compared to patients with low risk of CRS.

With respect to $\leq 3 \mathrm{~cm}$ liver metastasis, liver disease control between the two groups was similar, but it was worse in the ablation group than that in the resection group when the liver lesion size was $>3 \mathrm{~cm}$, supporting the results described by Tilborg et al. and Lee et al. that resection and ablation provided similar outcome in the treatment of CLOM cases with hepatic tumor size $\leq 3 \mathrm{~cm}$ (Lee et al. 2016; Van Tilborg et al. 2011). This highlighted the finding that ablation provided equal benefit to surgery for small liver lesion as was presented in other researches, which showed that ablation was as effective as resection in the treatment of other small with/non solitary malignant tumors (Chen et al. 2006; Uhlig et al. 2018).

There are some limitations in our study. First, the retrospective nature and a limited number of patients from single center made our finding need to be validated in other prospective trials. Second, 131 patients were excluded from the final cohort after PSM, leading to raw data distortion. However, the baseline data before further analysis were more balanced; thus, avoiding amplification of a biased conclusion. Third, liver metastases in the ablation group were diagnosed on the basis of CEA and contrast enhancement of CT or MRI, lacking of histopathologic evaluation of the target area, as some published reports had described that such an examination could identify important information about tumor biology and the potential risk for progression before or after treatment (Motoyoshi et al. 2010; Sofocleous et al. 2013). Moreover, cases with molecular characteristics such as KRAS and microsatellite test (data not shown) were limited in our cohort, and they might be helpful to predict and evaluate the prognostic outcome in these patients. Finally, we did not compare the difference in lesion location and depth in the liver as they were not included in the CRS analysis. Although some authors considered that location might not influence the oncologic outcome (Chen et al. 2018), the depth might affect the decision on resection or ablation, and treatment efficacy, as the deeper the lesion, the higher the risk and the more the difficulty for complete eradication of the lesion.

Peer) reviewing PDF | (2019:08:40501:1:1:NEW 18 Nov 2019) 


\section{Conclusion}

290 This retrospective study investigating the outcome in CLOM patients with liver lesion number $\leq 5$ and size $\leq 5 \mathrm{~cm}$,

291 which was resectable-ablative, indicated that resection could result in longer liver recurrence-free survival than 292 ablation when the size was $>3 \mathrm{~cm}$ or there was a high risk of CRS. But for $\leq 3 \mathrm{~cm}$ liver metastases, their treatment 293 efficacies were comparable. 
295

296

297

298

299

300

301

302

303

304

305

306

307

308

309

310

311

312

313

314

315

316

317

318

319

320

321

322

323

324

325

326

327

328

329

330

331

332

333

334

335

\section{References:}

Abdalla EK, Vauthey JN, Ellis LM, Ellis V, Pollock R, Broglio KR, Hess K, and Curley SA. 2004. Recurrence and outcomes following hepatic resection, radiofrequency ablation, and combined resection/ablation for colorectal liver metastases. Ann surg 239:818-825; discussion 825-817. 10.1097/01.sla.0000128305.90650.71

Chan AK, Hegarty C, Klass D, Yoshida E, Chung S, Liu DM, Ho SG, and Harris AC. 2015. The Role of Contrastenhanced Ultrasound in Guiding Radiofrequency Ablation of Hepatocellular Carcinoma: A Retrospective Study. Can Assoc Radiol J 66:171-178. 10.1016/j.carj.2014.11.005

Chen J, Peng K, Hu D, Shen J, Zhou Z, Xu L, Chen J, Pan Y, Wang J, Zhang Y, and Chen M. 2018. Tumor Location Influences Oncologic Outcomes of Hepatocellular Carcinoma Patients Undergoing Radiofrequency Ablation. Cancers (Basel) 10. 10.3390/cancers10100378

Chen MS, Li JQ, Zheng Y, Guo RP, Liang HH, Zhang YQ, Lin XJ, and Lau WY. 2006. A prospective randomized trial comparing percutaneous local ablative therapy and partial hepatectomy for small hepatocellular carcinoma. Ann Surg 243:321-328. 10.1097/01.sla.0000201480.65519.b8

Chua TC, Saxena A, Chu F, Zhao J, and Morris DL. 2011. Predictors of cure after hepatic resection of colorectal liver metastases: an analysis of actual 5- and 10-year survivors. J Surg Oncol 103:796-800. 10.1002/jso.21864

Cirocchi R, Trastulli S, Boselli C, Montedori A, Cavaliere D, Parisi A, Noya G, and Abraha I. 2012. Radiofrequency ablation in the treatment of liver metastases from colorectal cancer. Cochrane Database Syst Rev:CD006317. 10.1002/14651858.CD006317.pub3

Dupre A, Jones RP, Diaz-Nieto R, Fenwick SW, Poston GJ, and Malik HZ. 2017. Curative-intent treatment of recurrent colorectal liver metastases: A comparison between ablation and resection. Eur J Surg Oncol 43:1901-1907. 10.1016/j.ejso.2017.08.008

Evrard S, Rivoire M, Arnaud JP, Lermite E, Bellera C, Fonck M, Becouarn Y, Lalet C, Pulido M, and MathoulinPelissier S. 2012. Unresectable colorectal cancer liver metastases treated by intraoperative radiofrequency ablation with or without resection. British Journal of Surgery 99:558-565. 10.1002/bjs.8665

Fong Y, Fortner J, Sun RL, Brennan MF, and Blumgart LH. 1999. Clinical score for predicting recurrence after hepatic resection for metastatic colorectal cancer: analysis of 1001 consecutive cases. Ann Surg 230:309-318; discussion 318-321. 10.1097/00000658-199909000-00004

Gillams AR, and Lees WR. 2009. Five-year survival in 309 patients with colorectal liver metastases treated with radiofrequency ablation. Eur Radiol 19:1206-1213. 10.1007/s00330-008-1258-5

Gurusamy K, Corrigan N, Croft J, Twiddy M, Morris S, Woodward N, Bandula S, Hochhauser D, Napp V, Pullan A, Jakowiw N, Prasad R, Damink SO, van Laarhoven C, de Wilt JHW, Brown J, and Davidson BR. 2018. Liver resection surgery versus thermal ablation for colorectal LiVer MetAstases (LAVA): study protocol for a randomised controlled trial. Trials 19:105. 10.1186/s13063-018-2499-5

Hur H, Ko YT, Min BS, Kim KS, Choi JS, Sohn SK, Cho CH, Ko HK, Lee JT, and Kim NK. 2009. Comparative study of resection and radiofrequency ablation in the treatment of solitary colorectal liver metastases. Am J Surg 197:728-736. 10.1016/j.amjsurg.2008.04.013

Kumar G, Goldberg SN, Gourevitch S, Levchenko T, Torchilin V, Galun E, and Ahmed M. 2018. Targeting STAT3 to 
Suppress Systemic Pro-Oncogenic Effects from Hepatic Radiofrequency Ablation. Radiology 286:524-536. 10.1148/radiol.2017162943

Lee BC, Lee HG, Park IJ, Kim SY, Kim KH, Lee JH, Kim CW, Lee JL, Yoon YS, Lim SB, Yu CS, and Kim JC. 2016. The role of radiofrequency ablation for treatment of metachronous isolated hepatic metastasis from colorectal cancer. Medicine (Baltimore) 95:e4999. 10.1097/MD.0000000000004999

Lee H, Heo JS, Cho YB, Yun SH, Kim HC, Lee WY, Choi SH, and Choi DW. 2015. Hepatectomy vs radiofrequency ablation for colorectal liver metastasis: a propensity score analysis. World J Gastroenterol 21:3300-3307. 10.3748/wjg.v21.i11.3300

Lee WS, Yun SH, Chun HK, Lee WY, Kim SJ, Choi SH, Heo JS, Joh JW, Choi D, Kim SH, Rhim H, and Lim HK. 2008. Clinical outcomes of hepatic resection and radiofrequency ablation in patients with solitary colorectal liver metastasis. J Clin Gastroenterol 42:945-949. 10.1097/MCG.0b013e318064e752

Lin J, Peng J, Zhao Y, Luo B, Zhao Y, Deng Y, Sui Q, Gao Y, Zeng Z, Lu Z, and Pan Z. 2018. Early recurrence in patients undergoing curative resection of colorectal liver oligometastases: identification of its clinical characteristics, risk factors, and prognosis. J Cancer Res Clin Oncol 144:359-369. 10.1007/s00432-0172538-8

Meijerink MR, Puijk RS, and van den Tol PMP. 2019. COLLISION Trial Seeks to Answer Time-Honored Question: "Thermal Ablation or Surgery for Colorectal Liver Metastases?". Cardiovasc Intervent Radiol. 10.1007/s00270-019-02236-3

Motoyoshi A, Noguchi M, Earashi M, Zen Y, and Fujii H. 2010. Histopathological and immunohistochemical evaluations of breast cancer treated with radiofrequency ablation. I Surg Oncol 102:385-391. $10.1002 / \mathrm{jso} .21429$

Ni Y, Yang X, Cui J, Li Z, Yang P, Xu J, Shan G, and Ye X. 2019. Combined microwave ablation and antiangiogenic therapy to increase local efficacy. Minim Invasive Ther Allied Technol:1-7. 10.1080/13645706.2019.1601632

Otto G, Duber C, Hoppe-Lotichius M, Konig J, Heise M, and Pitton MB. 2010. Radiofrequency ablation as first-line treatment in patients with early colorectal liver metastases amenable to surgery. Ann Surg 251:796-803. 10.1097/SLA.0b013e3181bc9fae

Park IJ, Kim HC, Yu CS, Kim PN, Won HJ, and Kim JC. 2008. Radiofrequency ablation for metachronous liver metastasis from colorectal cancer after curative surgery. Ann Surg Oncol 15:227-232. 10.1245/s10434007-9625-z

Peng Z, Chen S, Xiao H, Wang Y, Li J, Mei J, Chen Z, Zhou Q, Feng S, Chen M, Qian G, Peng S, and Kuang M. 2019. Microvascular Invasion as a Predictor of Response to Treatment with Sorafenib and Transarterial Chemoembolization for Recurrent Intermediate-Stage Hepatocellular Carcinoma. Radiology 292:237-247. 10.1148/radiol.2019181818

Shady W, Petre EN, Gonen M, Erinjeri JP, Brown KT, Covey AM, Alago W, Durack JC, Maybody M, Brody LA, Siegelbaum RH, D'Angelica MI, Jarnagin WR, Solomon SB, Kemeny NE, and Sofocleous CT. 2016. Percutaneous Radiofrequency Ablation of Colorectal Cancer Liver Metastases: Factors Affecting Outcomes--A 10-year Experience at a Single Center. Radiology 278:601-611. 10.1148/radiol.2015142489

Siegel RL, Miller KD, and Jemal A. 2019. Cancer statistics, 2019. CA Cancer J Clin 69:7-34. 10.3322/caac.21551

Siperstein AE, Berber E, Ballem N, and Parikh RT. 2007. Survival after radiofrequency ablation of colorectal liver metastases: 10-year experience. Ann Surg 246:559-565; discussion 565-557. 


\subsection{7/SLA.0b013e318155a7b6}

Sofocleous CT, Garg SK, Cohen P, Petre EN, Gonen M, Erinjeri JP, Downey RJ, Travis WD, and Solomon SB. 2013. Ki 67 is an independent predictive biomarker of cancer specific and local recurrence-free survival after lung tumor ablation. Ann Surg Oncol 20 Suppl 3:S676-683. 10.1245/s10434-013-3140-1

Sofocleous CT, Petre EN, Gonen M, Brown KT, Solomon SB, Covey AM, Alago W, Brody LA, Thornton RH, D'Angelica $\mathrm{M}$, Fong $\mathrm{Y}$, and Kemeny NE. 2011. CT-guided radiofrequency ablation as a salvage treatment of colorectal cancer hepatic metastases developing after hepatectomy. I Vasc Interv Radiol 22:755-761. 10.1016/j.jvir.2011.01.451

Solbiati L, Ahmed M, Cova L, lerace T, Brioschi M, and Goldberg SN. 2012. Small liver colorectal metastases treated with percutaneous radiofrequency ablation: local response rate and long-term survival with up to 10-year follow-up. Radiology 265:958-968. 10.1148/radiol.12111851

Sotirchos VS, Petrovic LM, Gonen M, Klimstra DS, Do RK, Petre EN, Garcia AR, Barlas A, Erinjeri JP, Brown KT, Covey AM, Alago W, Brody LA, DeMatteo RP, Kemeny NE, Solomon SB, Manova-Todorova KO, and Sofocleous CT. 2016. Colorectal Cancer Liver Metastases: Biopsy of the Ablation Zone and Margins Can Be Used to Predict Oncologic Outcome. Radiology 280:949-959. 10.1148/radiol.2016151005

Stattner S, Jones RP, Yip VS, Buchanan K, Poston GJ, Malik HZ, and Fenwick SW. 2013. Microwave ablation with or without resection for colorectal liver metastases. Eur J Surg Oncol 39:844-849. 10.1016/j.ejso.2013.04.005

Takahashi H, Kahramangil B, Kose E, and Berber E. 2018. A comparison of microwave thermosphere versus radiofrequency thermal ablation in the treatment of colorectal liver metastases. HPB (Oxford) 20:11571162. 10.1016/j.hpb.2018.05.012

Uhlig J, Kokabi N, Xing M, and Kim HS. 2018. Ablation versus Resection for Stage 1A Renal Cell Carcinoma: National Variation in Clinical Management and Selected Outcomes. Radiology 288:889-897. 10.1148/radiol.2018172960

Van Cutsem E, Cervantes A, Adam R, Sobrero A, Van Krieken JH, Aderka D, Aranda Aguilar E, Bardelli A, Benson A, Bodoky G, Ciardiello F, D'Hoore A, Diaz-Rubio E, Douillard JY, Ducreux M, Falcone A, Grothey A, Gruenberger T, Haustermans K, Heinemann V, Hoff P, Kohne CH, Labianca R, Laurent-Puig P, Ma B, Maughan T, Muro K, Normanno N, Osterlund P, Oyen WJ, Papamichael D, Pentheroudakis G, Pfeiffer P, Price TJ, Punt C, Ricke J, Roth A, Salazar R, Scheithauer W, Schmoll HJ, Tabernero J, Taieb J, Tejpar S, Wasan H, Yoshino T, Zaanan A, and Arnold D. 2016. ESMO consensus guidelines for the management of patients with metastatic colorectal cancer. Ann Oncol 27:1386-1422. 10.1093/annonc/mdw235

Van Cutsem E, Cervantes A, Nordlinger B, Arnold D, and Group EGW. 2014. Metastatic colorectal cancer: ESMO Clinical Practice Guidelines for diagnosis, treatment and follow-up. Ann Oncol 25 Suppl 3:iii1-9. 10.1093/annonc/mdu260

Van Tilborg AA, Meijerink MR, Sietses C, Van Waesberghe JH, Mackintosh MO, Meijer S, Van Kuijk C, and Van Den Tol P. 2011. Long-term results of radiofrequency ablation for unresectable colorectal liver metastases: a potentially curative intervention. Br J Radiol 84:556-565. 10.1259/bjr/78268814

Wang L, Zhang ZY, Yan XL, Yang W, Yan K, and Xing BC. 2018. Radiofrequency ablation versus resection for technically resectable colorectal liver metastasis: a propensity score analysis. World J Surg Oncol 16:207. 10.1186/s12957-018-1494-3

Zhang R, Ma M, Dong G, Yao RR, Li JH, Zheng QD, Dong YY, Ma H, Gao DM, Cui JF, Ren ZG, and Chen RX. 2017. Increased matrix stiffness promotes tumor progression of residual hepatocellular carcinoma after 


\section{Table $\mathbf{1}$ (on next page)}

Table 1 Baseline characteristics of patients treated with resection or ablation before PSM.

${ }^{a}$ Data of 344 patients were available ${ }^{b}$ Data of 184 patients were available PSM Propensity score matching, IVTT Intravascular tumor thrombus 
1 Table 1 Baseline characteristics of patients treated with resection or ablation before PSM

\begin{tabular}{|c|c|c|c|}
\hline Characteristics & Resection $(\mathrm{n}=250, \%)$ & Ablation $(\mathrm{n}=171, \%)$ & $P$ value \\
\hline \multicolumn{4}{|l|}{ Age } \\
\hline Average & $55.68 \pm 10.64$ & $56.58 \pm 13.15$ & 0.385 \\
\hline$\leq 60$ & $161(64.4)$ & $103(60.2)$ & \\
\hline$>60$ & $89(35.6)$ & $68(39.8)$ & \\
\hline Gender & & & 0.285 \\
\hline Male & $163(65.2)$ & $120(70.2)$ & \\
\hline Female & $87(34.8)$ & $51(29.8)$ & \\
\hline Comorbidity & & & 0.766 \\
\hline No & $144(57.6)$ & $96(56.1)$ & \\
\hline Yes & $106(42.4)$ & $75(43.9)$ & \\
\hline Primary tumor side & & & 0.914 \\
\hline Left-side colorectum & $197(78.8)$ & $134(78.4)$ & \\
\hline Right-side colon & $53(21.2)$ & $37(21.6)$ & \\
\hline \multicolumn{4}{|l|}{ TNM stage } \\
\hline T stage & & & 0.067 \\
\hline $1-3$ & $122(48.8)$ & $68(39.8)$ & \\
\hline 4 & $128(51.2)$ & $103(60.2)$ & \\
\hline $\mathrm{N}$ stage & & & 0.183 \\
\hline 0 & $113(45.2)$ & $64(37.4)$ & \\
\hline 1 & $96(38.4)$ & $69(40.4)$ & \\
\hline 2 & $41(16.4)$ & $38(22.2)$ & \\
\hline IVTT $^{\mathrm{a}}$ & & & 0.734 \\
\hline Positive & $89(35.6)$ & $51(29.8)$ & \\
\hline Negative & $126(50.4)$ & $78(45.6)$ & \\
\hline Differentiation (primary) & & & 0.446 \\
\hline Poor & $58(23.2)$ & $35(20.5)$ & \\
\hline Moderate & 181(72.4) & $124(72.5)$ & \\
\hline Well & $11(4.4)$ & $12(7.0)$ & \\
\hline Metastases diameter $(\mathrm{cm})$ & & & 0.001 \\
\hline$\leq 3$ & $189(75.6)$ & $152(88.9)$ & \\
\hline$>3, \leq 5$ & $61(24.4)$ & $19(11.1)$ & \\
\hline Metastases number & & & 0.561 \\
\hline 1 & $126(50.4)$ & $88(51.5)$ & \\
\hline 2 & $56(22.4)$ & $45(26.3)$ & \\
\hline 3 & $33(13.2)$ & $16(9.3)$ & \\
\hline $4-5$ & $35(14.0)$ & $22(12.9)$ & \\
\hline
\end{tabular}




\begin{tabular}{lccc}
\hline Metastases distribution & & & 0.921 \\
Unilobar & $137(54.8)$ & $95(55.6)$ & \\
Multilobar (>1 lobe) & $113(45.2)$ & $76(44.4)$ & 0.855 \\
Preoperative chemotherapy & & & \\
No & $84(33.6)$ & $56(32.7)$ & \\
Yes & $166(66.4)$ & $115(67.3)$ & \\
Postoperative chemotherapy & & & \\
No & $22(8.8)$ & $42(24.6)$ & \\
Yes & $228(91.2)$ & $129(75.4)$ & \\
KRAS status & & & 0.391 \\
Wild type & $71(28.4)$ & $49(28.7)$ & \\
Mutation type & $42(16.8)$ & $22(12.9)$ & \\
CEA level (ng/ml) & & & \\
$\leq 5$ & $111(44.4)$ & $97(45.0)$ & 0.099 \\
$>5$ & $139(55.6)$ & $94(55.0)$ & \\
Timing of metastasis (months) & & $30(17.5)$ & \\
Synchronous $(<12)$ & $29(11.6)$ & $141(82.5)$ & \\
Metachronous $(\geq 12)$ & $221(88.4)$ & & \\
\hline
\end{tabular}

$2{ }^{a}$ Data of 344 patients were available

$3 \quad{ }^{\mathrm{b}}$ Data of 184 patients were available

4 PSM Propensity score matching, IVTT Intravascular tumor thrombus

5 


\section{Table 2 (on next page)}

Table 2 Baseline characteristics of patients treated with resection or ablation after PSM.

${ }^{a}$ Data of 239 patients were available ${ }^{b}$ Data of 123 patients were available PSM Propensity score matching; IVTT Intravascular tumor thrombus 
1 Table 2 Baseline characteristics of patients treated with resection or ablation after PSM

\begin{tabular}{|c|c|c|c|}
\hline Characteristics & Resection $(\mathrm{n}=145, \%)$ & Ablation $(\mathrm{n}=145, \%)$ & $P$ value \\
\hline \multicolumn{4}{|l|}{ Age } \\
\hline Average & $57.15 \pm 10.26$ & $56.04 \pm 13.22$ & 0.629 \\
\hline$\leq 60$ & $87(60)$ & $91(62.8)$ & \\
\hline$>60$ & $58(40)$ & $54(37.2)$ & \\
\hline Gender & & & 0.524 \\
\hline Male & $98(67.6)$ & $103(71.0)$ & \\
\hline Female & $47(32.4)$ & $42(29.0)$ & \\
\hline Comorbidity & & & 0.556 \\
\hline No & $76(52.4)$ & $81(55.9)$ & \\
\hline Yes & $69(47.6)$ & $64(44.1)$ & \\
\hline Primary tumor side & & & 0.779 \\
\hline Left-side colorectum & 111(76.6) & $113(77.9)$ & \\
\hline Right-side colon & $34(23.4)$ & $32(22.1)$ & \\
\hline \multicolumn{4}{|l|}{ TNM stage } \\
\hline T stage & & & 0.158 \\
\hline $1-3$ & $73(50.3)$ & $61(42.1)$ & \\
\hline 4 & $72(49.7)$ & $84(57.9)$ & \\
\hline $\mathrm{N}$ stage & & & 0.583 \\
\hline 0 & $59(40.7)$ & $62(42.8)$ & \\
\hline 1 & $59(40.7)$ & $51(35.1)$ & \\
\hline 2 & $27(18.6)$ & $32(22.1)$ & \\
\hline IVTT $^{\mathrm{a}}$ & & & 0.623 \\
\hline Positive & $53(36.6)$ & $44(30.3)$ & \\
\hline Negative & $73(50.3)$ & $69(47.6)$ & \\
\hline Differentiation (primary) & & & 0.500 \\
\hline Poor & $35(24.1)$ & $28(19.3)$ & \\
\hline Moderate & $100(69.0)$ & $109(75.2)$ & \\
\hline Well & $10(6.9)$ & $8(5.5)$ & \\
\hline Metastases diameter $(\mathrm{cm})$ & & & 0.857 \\
\hline$\leq 3$ & $128(88.3)$ & $127(87.6)$ & \\
\hline$>3, \leq 5$ & $17(11.7)$ & $18(12.4)$ & \\
\hline Metastases number & & & 0.459 \\
\hline 1 & $77(53.1)$ & $73(50.3)$ & \\
\hline 2 & $30(20.7)$ & $40(27.6)$ & \\
\hline 3 & $20(13.8)$ & $14(9.7)$ & \\
\hline $4-5$ & $18(12.4)$ & $18(12.4)$ & \\
\hline
\end{tabular}




\begin{tabular}{|c|c|c|c|}
\hline Metastases distribution & & & 1.000 \\
\hline Unilobar & $79(54.5)$ & $79(54.5)$ & \\
\hline Multilobar (>1 lobe) & $66(45.5)$ & $66(45.5)$ & \\
\hline Preoperative chemotherapy & & & 0.616 \\
\hline No & $49(33.8)$ & $45(31.0)$ & \\
\hline Yes & $96(66.2)$ & $100(69.0)$ & \\
\hline Postoperative chemotherapy & & & 0.860 \\
\hline No & $18(12.4)$ & $19(13.1)$ & \\
\hline Yes & $127(87.6)$ & $126(86.9)$ & \\
\hline KRAS status ${ }^{b}$ & & & 0.652 \\
\hline Wild type & $41(28.3)$ & $44(30.3)$ & \\
\hline Mutation type & $20(13.8)$ & $18(12.4)$ & \\
\hline CEA level (ng/ml) & & & 0.724 \\
\hline$\leq 5$ & $65(44.8)$ & $68(46.9)$ & \\
\hline$>5$ & $80(55.2)$ & $77(53.1)$ & \\
\hline Timing of metastasis (months) & & & 1.000 \\
\hline Synchronous $(<12)$ & $18(12.4)$ & $18(12.4)$ & \\
\hline Metachronous $(\geq 12)$ & $127(87.6)$ & $127(87.6)$ & \\
\hline
\end{tabular}

$2{ }^{a}$ Data of 239 patients were available

$3 \quad{ }^{\mathrm{b}}$ Data of 123 patients were available

4 PSM Propensity score matching; IVTT Intravascular tumor thrombus

5 


\section{Table 3 (on next page)}

Table 3 Recurrence and complication evaluation between resection and ablation.

${ }^{\text {a }}$ Comparison between the two groups with and without liver recurrence was made by the $\chi^{2}$ test ${ }^{b}$ Includes 8 patients with a combined LNM in the resection group ${ }^{c}$ Includes 22 patients with a combined LNM in the ablation group ${ }^{d}$ Data of 67 patients were available ${ }^{\mathrm{e}}$ Data of 88 patients were available ${ }^{f}$ Comparison between the two groups was made by the Student $t$ test LTR local tumor recurrence, $L N M$ liver new metastasis, EHR extrahepatic recurrence 
1 Table 3 Recurrence and complication evaluation between resection and ablation

Resection $(\mathrm{n}=145, \quad$ Ablation $(\mathrm{n}=145, \%) \quad P$ value

$\%)$

\begin{tabular}{|c|c|c|c|}
\hline \multicolumn{4}{|l|}{ Recurrence Pattern } \\
\hline Total (liver) $^{\mathrm{a}}$ & $67(46.2)$ & $88(60.7)$ & $0.013^{\mathrm{a}}$ \\
\hline LTR & $22(32.8)^{\mathrm{b}}$ & $59(67.0)^{c}$ & $<0.001$ \\
\hline LNM & $45(67.2)$ & $29(33.0)$ & \\
\hline EHR only & $13(9.0)$ & $10(6.9)$ & \\
\hline Early liver recurrence & $25(37.3)^{\mathrm{d}}$ & $24(27.3)^{\mathrm{e}}$ & 0.223 \\
\hline \multicolumn{4}{|l|}{ Recurrence Number (liver) } \\
\hline Mean & $2.06 \pm 1.19$ & $2.06 \pm 1.26$ & $0.637^{\mathrm{f}}$ \\
\hline 1 & 31 & 43 & \\
\hline 2 & 15 & 17 & \\
\hline 3 & 7 & 8 & \\
\hline$>3$ & 14 & 20 & \\
\hline \multicolumn{4}{|l|}{ Complication } \\
\hline Total & $19(13.1)$ & $15(10.3)$ & 0.465 \\
\hline Peritonitis & 2 & 1 & \\
\hline Pleural effusion & 1 & 1 & \\
\hline Death & 2 & & \\
\hline Chylous fistula & 3 & & \\
\hline Biliary fistula & 1 & & \\
\hline Intestinal obstruction & 2 & & \\
\hline Liver function failure & 2 & & \\
\hline Liver abscess & 1 & & \\
\hline Cardiac insufficiency & 5 & & \\
\hline Pneumothorax & & 2 & \\
\hline Subcapsular hematoma & & 2 & \\
\hline Infection & & 2 & \\
\hline Hydropneumothorax & & 1 & \\
\hline Pneumorrhagia & & 1 & \\
\hline Thrombocytopenia & & 1 & \\
\hline Empyrosis of the back skin & & 1 & \\
\hline Right shoulder pain & & 1 & \\
\hline
\end{tabular}




\section{Fever}

Nausea

2 a Comparison between the two groups with and without liver recurrence was made by the $\chi^{2}$ test

3 b Includes 8 patients with a combined LNM in the resection group

$4{ }^{\mathrm{c}}$ Includes 22 patients with a combined LNM in the ablation group

5 d Data of 67 patients were available

6 e Data of 88 patients were available

$7 \quad{ }^{\mathrm{f}}$ Comparison between the two groups was made by the Student $t$ test

8 LTR local tumor recurrence, $L N M$ liver new metastasis, EHR extrahepatic recurrence 


\section{Table 4(on next page)}

Table 4 Survival rates in the specific period.

OS Overall survival, LPFS Liver progression-free survival 
1 Table 4 Survival rates in the specific period

\begin{tabular}{lccccc}
\hline \multirow{2}{*}{ Survival } & \multicolumn{2}{c}{ OS } & & \multicolumn{2}{c}{ LPFS } \\
\cline { 2 - 3 } \cline { 5 - 6 } & Resection (\%) & Ablation (\%) & & Resection (\%) & Ablation (\%) \\
\cline { 2 - 3 } 1-year & 95.8 & 95.0 & & 64.5 & 50.8 \\
3-year & 69.8 & 60.1 & & 49.4 & 29.5 \\
5-year & 53.6 & 42.5 & & 36.5 & 24.3 \\
8-year & 45.1 & 32.9 & & & \\
10-year & 45.1 & - & & & \\
\hline
\end{tabular}

2 OS Overall survival, LPFS Liver progression-free survival

3 


\section{Table 5 (on next page)}

Table 5 Results of univariate and multivariate analyses of LPFS.

${ }^{a}$ Data of 239 patients were available ${ }^{b}$ Data of 123 patients were available LPFS Liver progression-free survival, HR Hazard ratio, IVTT Intravascular tumor thrombus, CEA Carcinoembryonic antigen. 
1 Table 5 Results of univariate and multivariate analyses of LPFS

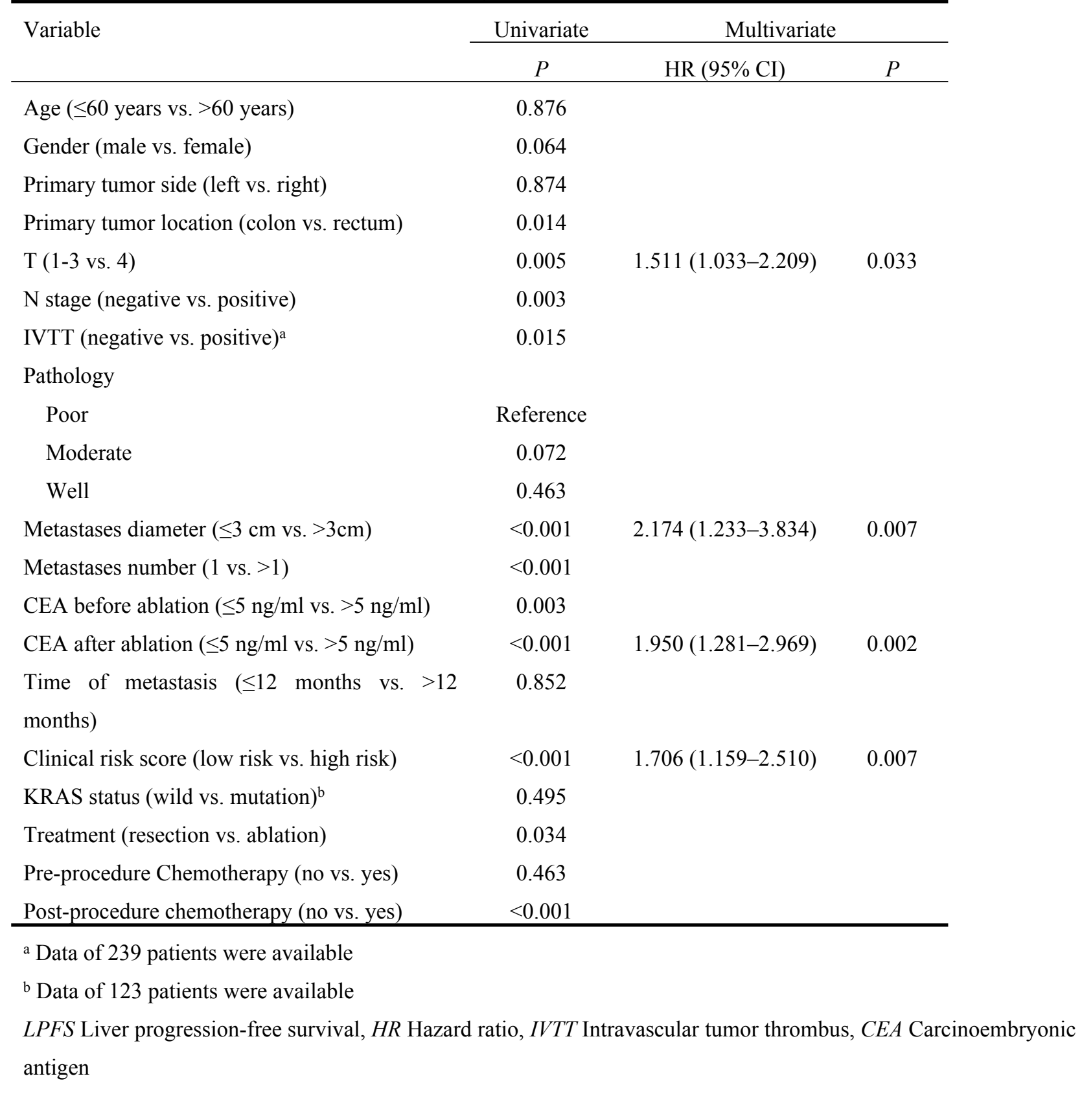




\section{Figure 1}

Interpretation of lesion with resectable-ablative characteristics.

Liver metastasis can be categorized as resectable but not ablative (a-c), unresectable nor unablative from a technical point of view, and resectable-ablative (resection or complete ablation) ( $d-f$ ) based on tumor size, location or distance with surrounding vital structure. (a-b) These two lesions $(6.8 \times 5.7 \mathrm{~cm}$ and $3.2 \times 3.1 \mathrm{~cm})$ were in Segment VII/VIII and the left lobe that was adjacent to the heart and stomach, respectively. They were suitable for resection but not for ablation due to their large size or proximity to the adjacent organ, which was high risk for tumor residual and complications. (c) The lesion $(2.7 \times 2.4 \mathrm{~cm})$ was located in Segment VII, compressing the right hepatic vein and the inferior vena cava. This lesion was suitable for resection but not for complete ablation due to its poor anatomic location resulting in highly recurrence. (d-f) These lesions, classified as resectable-ablative, could be treated by resection or complete ablation without the limit of the size, the location (beyond more than $1 \mathrm{~cm}$ from peripheral large vessel such as hepatic vein or portal vein) or difficulty from the procedure technique after obtaining consensus of a radiologist and a hepatobiliary surgeon. 


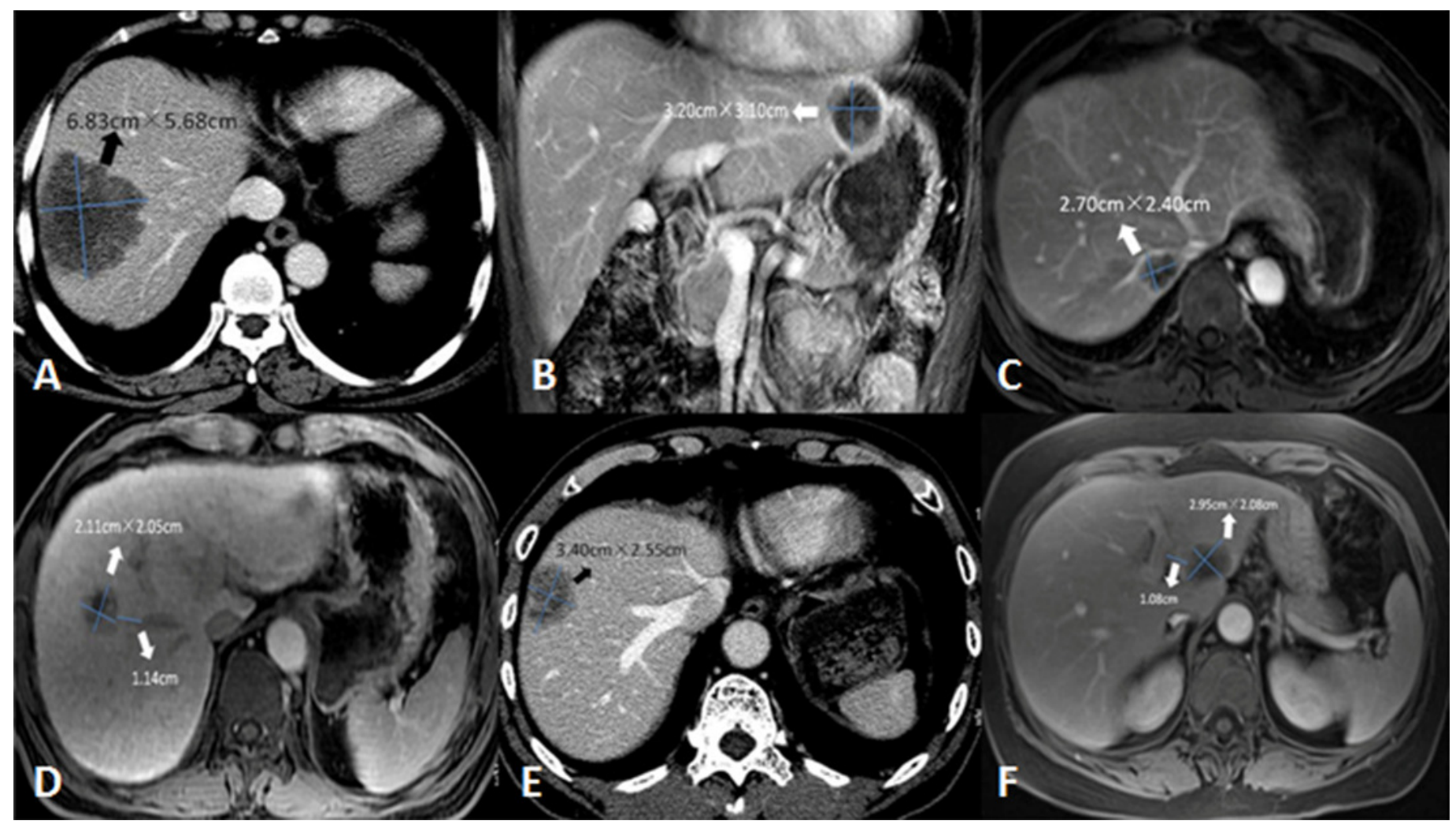


Figure 2

\section{Flowchart of selection of patients who underwent resection or ablation.}

\section{Flowchart of selection of patients who underwent resection or ablation.}

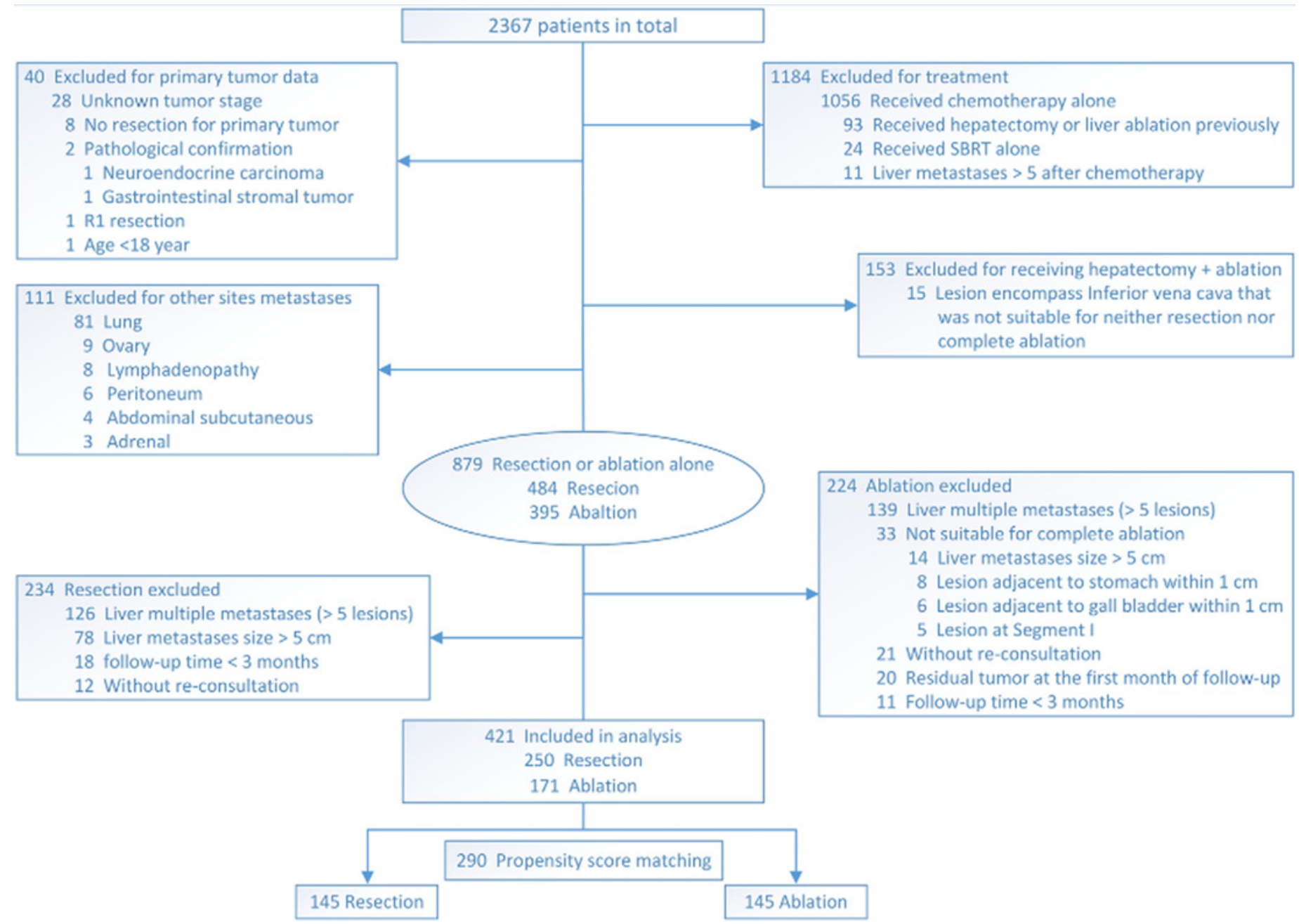


Figure 3

Recurrence parameters following resection and ablation.

Recurrence parameters following resection and ablation.LTR local tumor recurrence,LNM liver new metastasis

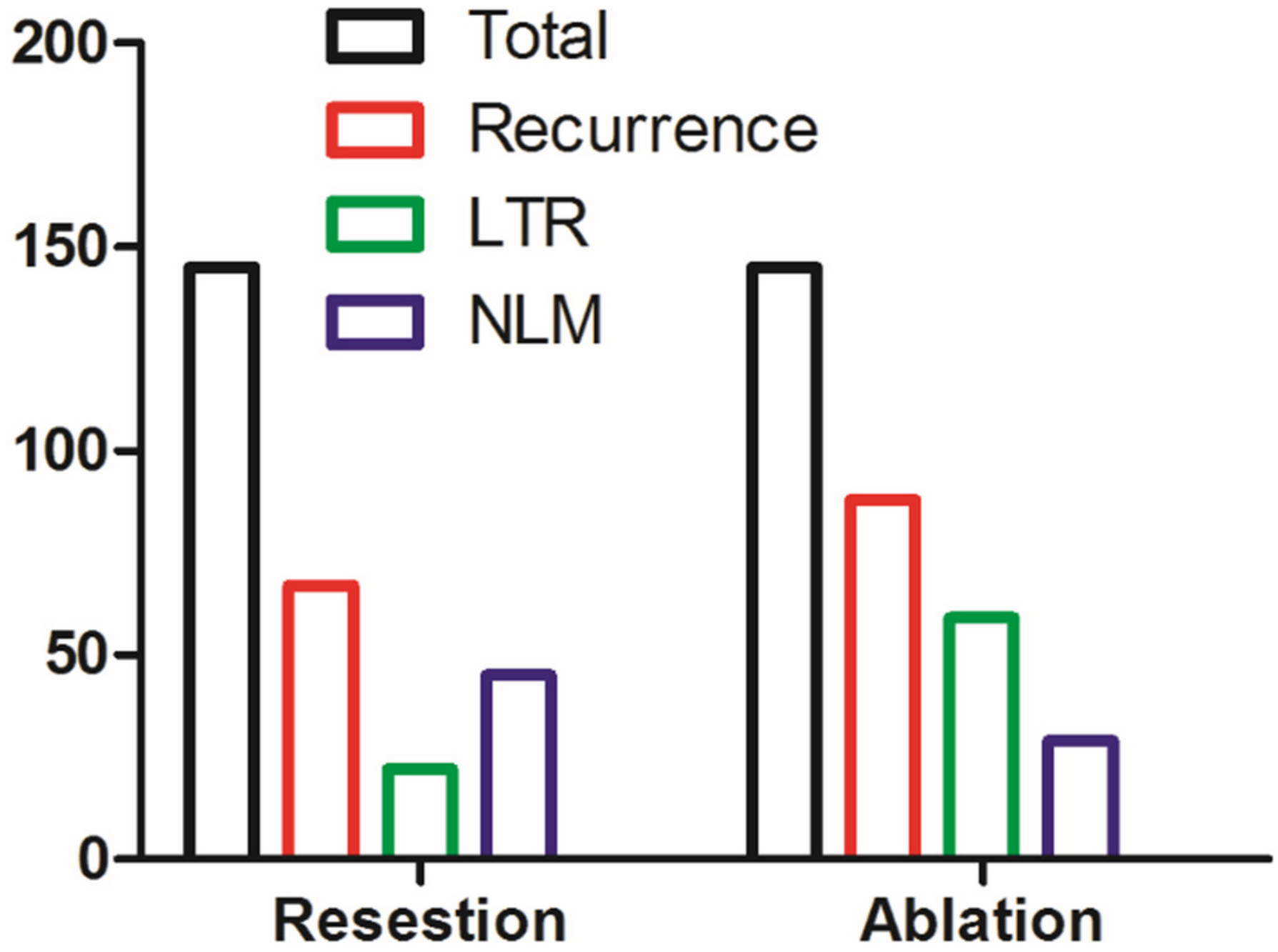


Figure 4

The OS and LPFS curves for patients with CLOM.

The OS and LPFS curves for patients with CLOM. OS between the resection and ablation groups were not significantly different before (a) and after (b) PSM. The LPFS between the resection and ablation groups was significantly different before (c) and after (d) PSM.OS Overall survival,LPFS Liver progression-free survival,CLOM Colorectal liver oligometastases,PSM Propensity score matching. 


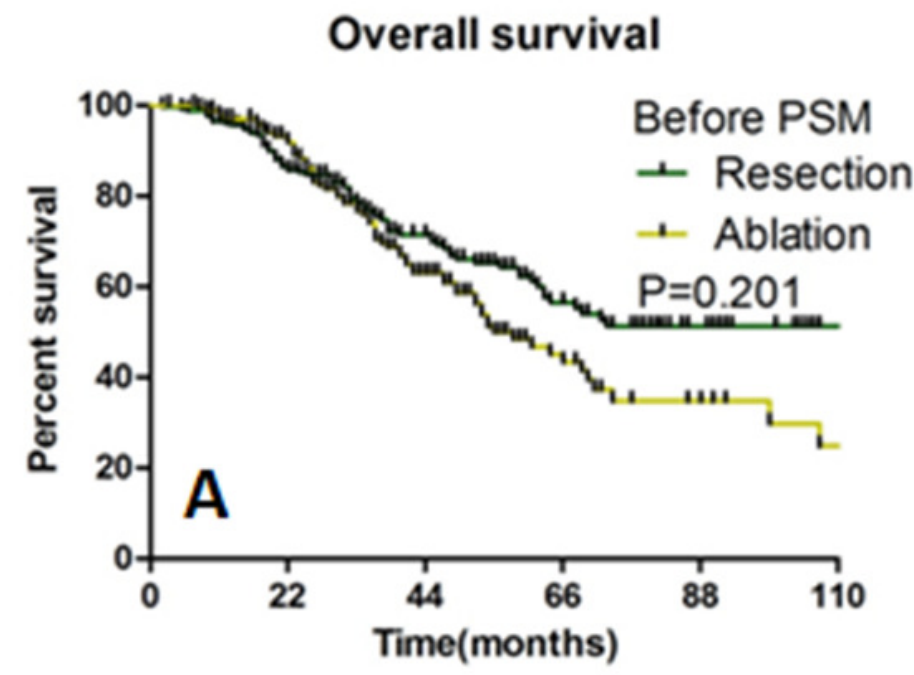

Number at risk

$\begin{array}{llllll}- & 182 & 99 & 48 & 22 & 7 \\ - & 135 & 63 & 26 & 11 & 6\end{array}$

Liver progression-free survival

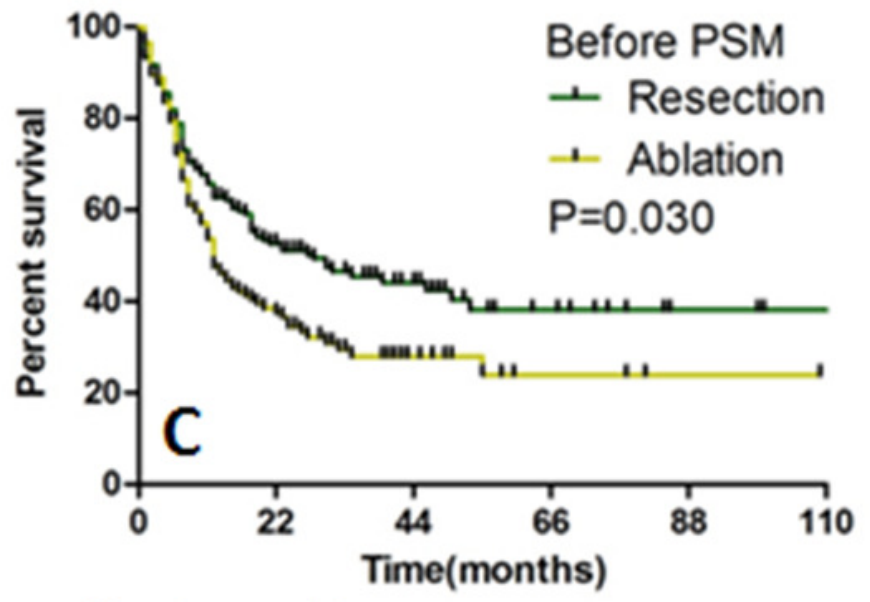

Number at risk

$\begin{array}{rrrrrr}- & 70 & 29 & 12 & 4 & 2 \\ - & 39 & 12 & 4 & 2 & 1\end{array}$

\section{Overall survival}

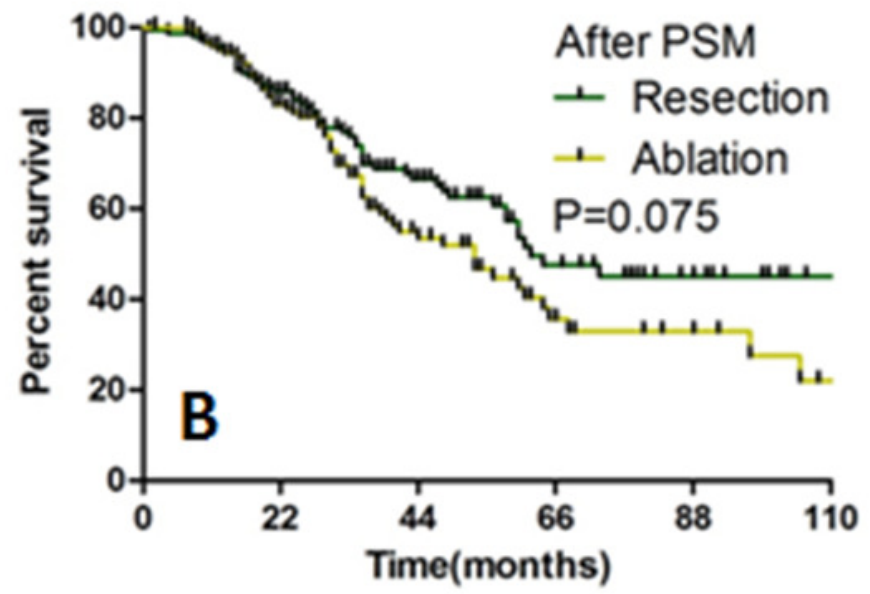

Number at risk

$\begin{array}{rrrrrr}- & 101 & 56 & 24 & 13 & 4 \\ - & 94 & 37 & 14 & 8 & 4\end{array}$

Liver progression-free survival

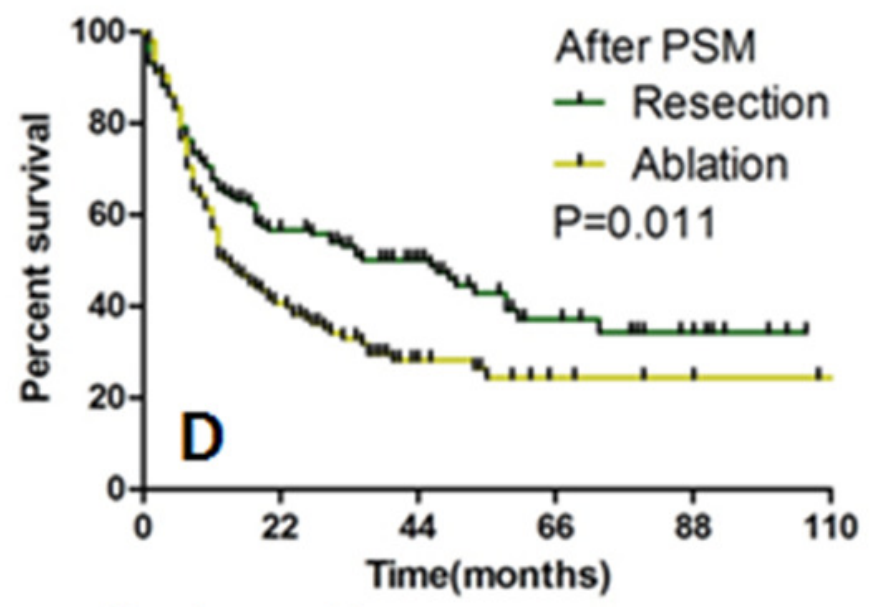

Number at risk

$\begin{array}{rrrrrr}- & 66 & 41 & 16 & 8 & 1 \\ - & 48 & 18 & 9 & 5 & 4\end{array}$


Figure 5

LPFS stratified by the size of liver metastases between the resection and ablation groups

LPFS stratified by the size of liver metastases between the resection and ablation groups. LPFS was significantly different before PSM for $\leq 3 \mathrm{~cm}$ solitary (a) and multiple lesions (b). After PSM, LPFS was not significantly different for $\leq 3 \mathrm{~cm}$ solitary (c) and multiple lesions (d), but was significantly longer in the resection group for $>3 \mathrm{~cm}$ lesion (e).LPFS Liver progression-free survival,PSM Propensity score matching.

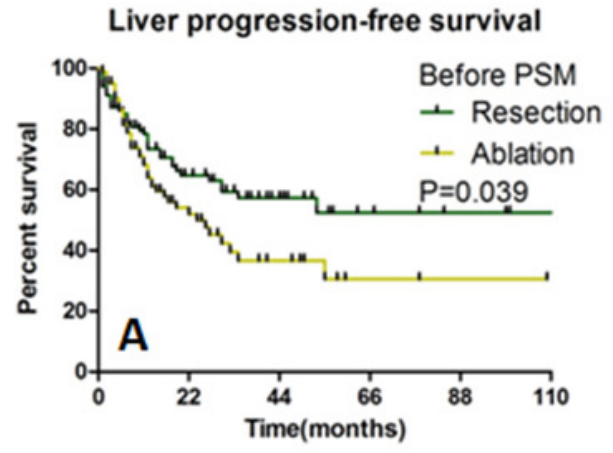

Number at risk

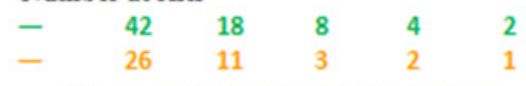

Liver progression-free survival

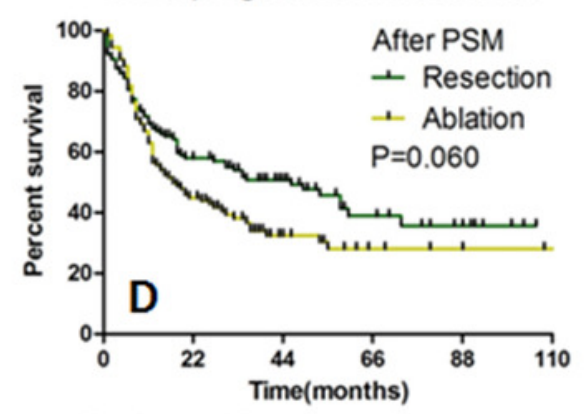

Number at risk

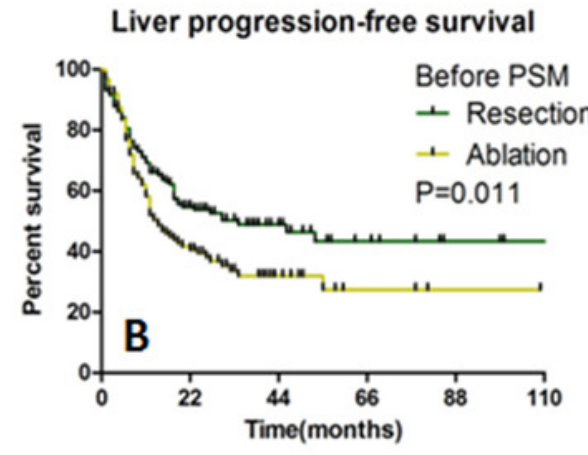

Number at risk

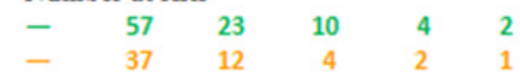

Liver progression-free survival

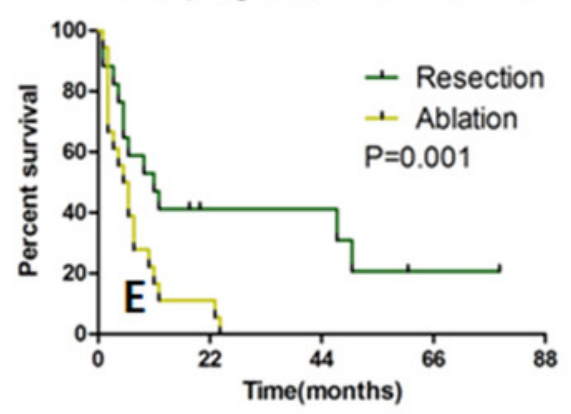

Number at risk

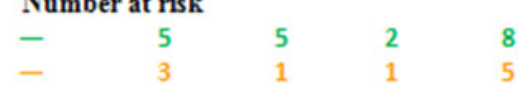

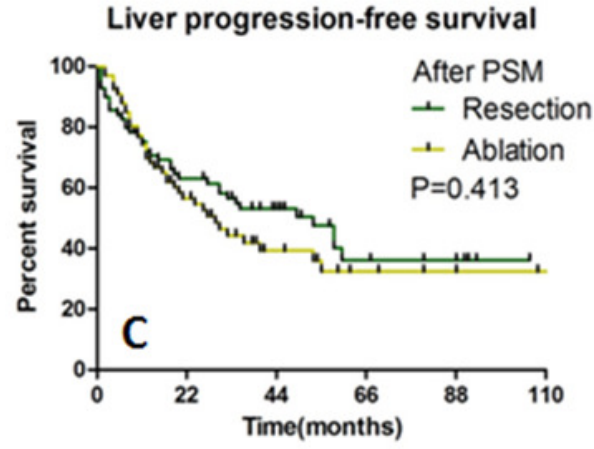

Number at risk

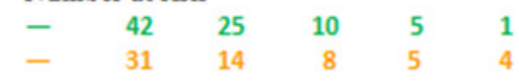




\section{Figure 6}

The OS and LPFS stratified by CRS and liver recurrence parameters.

The OS and LPFS stratified by CRS and liver recurrence parameters. LPFS was longer in the low risk of CRS than in the high risk of CRS (a). For the subgroup of high risk of CRS, LPFS was longer in the resection group than in the ablation group (b). The OS was better in patients without liver recurrence than in those with liver recurrence (c). The OS was better in patients without early liver recurrence than in those with early liver recurrence (d).OS Overall survival,LPFS Liver progression-free survival,CRS Clinical risk score. 
Liver progression-free survival

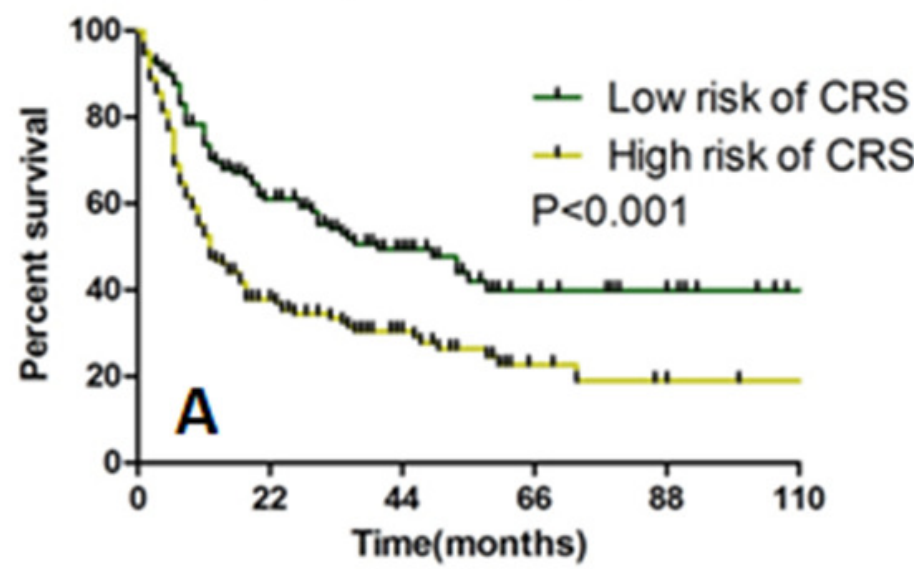

Number at risk

$\begin{array}{rrrrrr}- & 69 & 35 & 16 & 9 & 2 \\ - & 45 & 24 & 9 & 4 & 3\end{array}$

Overall survival

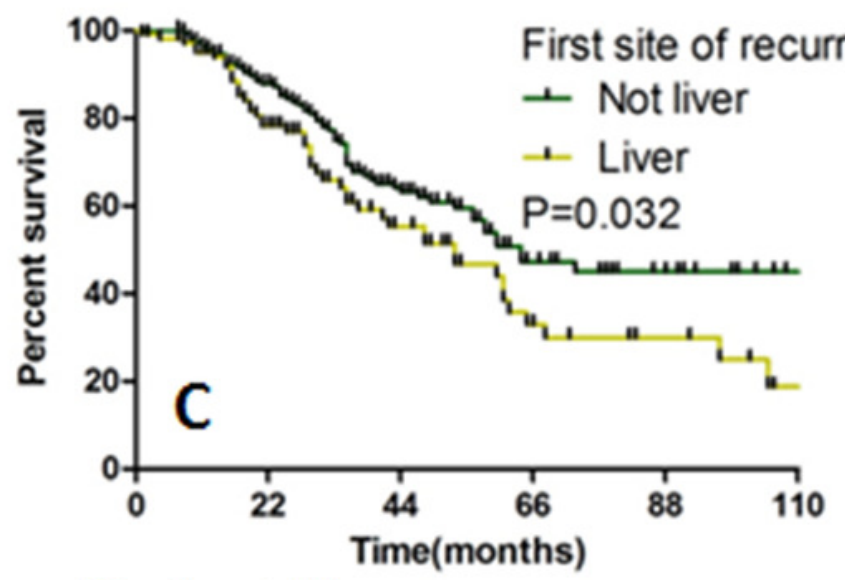

Number at risk

$\begin{array}{rrrrrr}- & 133 & 64 & 26 & 14 & 4 \\ - & 62 & 30 & 12 & 8 & 3\end{array}$

Liver progression-free survival

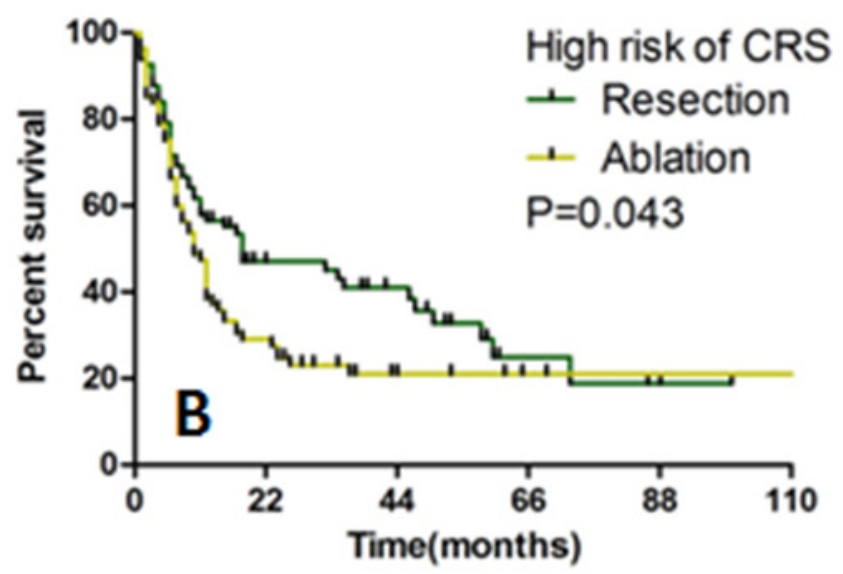

Number at risk

$\begin{array}{llllll}- & 25 & 17 & 5 & 2 & 1 \\ - & 21 & 8 & 5 & 4 & 4\end{array}$

Overall survival

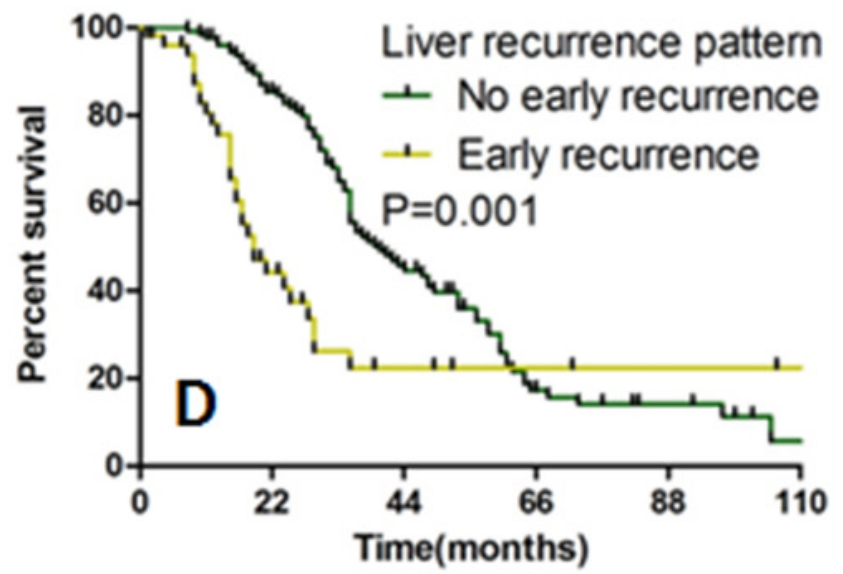

Number at risk

$\begin{array}{rrrrrr}- & 98 & 40 & 12 & 7 & 2 \\ - & 16 & 6 & 4 & 3 & 2\end{array}$


Figure 7

Forest plot for LPFS.

LPFS Liver progression-free survival,HR Hazard ratio,CRS Clinical risk score,DFI Disease-free interval,CEA Carcinoembryonic antigen.

Subgroup

HR (95\% CI)

Favors Favors

Resection Ablation

No chemotherapy post-treatment

Chemotherapy post-treatment

$0.599[0.289,1.241]$

CRS high risk

CRS low risk

$0.707[0.509,0.982]$

$0.677[0.455,0.952]$

Tumor size $(>3 \mathrm{~cm})$

$0.746[0.436,1.277]$

Tumor size $(\leq 3 \mathrm{~cm})$

$0.393[0.179,0.864]$

$\mathrm{DFI} \geq 12$ months

$0.726[0.523,1.008]$

DFI $<12$ months

$0.897[0.329,0.818]$

Pre-treatment CEA $(>5 \mathrm{ng} / \mathrm{ml})$

$0.750[0.545,1.032]$

Pre-treatment CEA ( $\leq 5 \mathrm{ng} / \mathrm{ml}$ )

$0.615[0.419,0.904]$

Lymph node positive

$0.743[0.460,1.199]$

Lymph node negative

T4

$0.772[0.535,1.114]$

$0.536[0.318,0.902]$

$\mathrm{T}(1-3)$

$0.892[0.611,1.304]$

$0.520[0.320,0.847]$
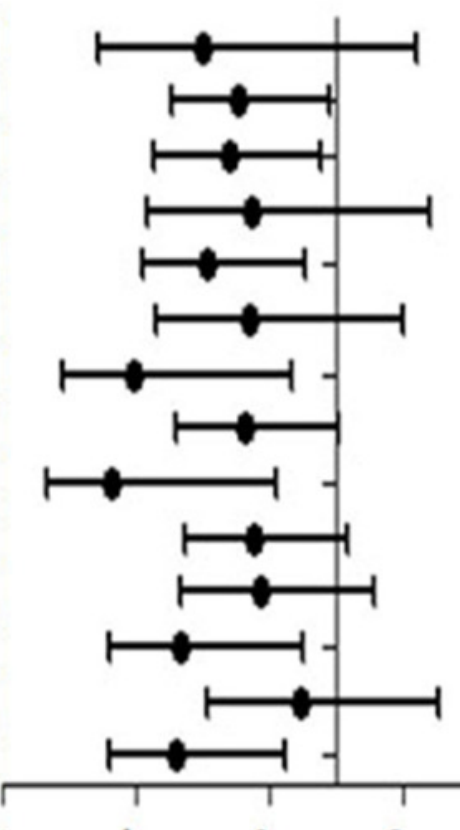

0.00

0.

1.2

$1 \cdot$

$\vartheta$ 